New focus on 'nudge' theories
State Digital over data being stuck in silos in the latter's systems. That runs counter to the common public story and makes the book much more than simply edited highlights of the public record.

Instead, the book accounts how campaigns are increasingly putting people at the centre of the marketing techniques — even if frequently only as numbers in an algorithm. The skills and research techniques documented in The Victory Lab are clearly very good for securing value for money from tactical campaign spending decisions. However, there is still the big question left: how much does such tactical finesse matter in determining the result of an election?

That wider question is implied, too, in the book's epilogue, which accounts how attention amongst some US political scientists and campaigns (especially Obama 2012) has now started to switch towards questions of voter psychology and trying to understand both what makes voters tick and therefore how best to nudge them in the right direction. They are starting from the idea of how to make a voter change their behaviour rather than how to raise the cost-efficiency of a campaign tactic.

That is where the future lies.

Mark Pack

\section{4 months in the life of data}

Journal of Direct, Data and Digital Marketing Practice (2013) 14, 353-358. doi:10.1057/dddmp.2013.27

Any review of the business and marketing world during 2012 has to make note of the rise of data. From being a backroom activity of interest only to specialists, it became a firm boardroom favourite, driven by a number of core concerns as well as new initiatives and opportunities. As chair of the IDM Data Council, James Morgan, Head of Information Strategy and Management, Business Intelligence, Telefónica, UK, said: 'Last year we saw the rising importance of the debate around privacy. You could see that in the way the media gave it coverage it never did before'.

To identify what brought about this change - and whether it will continue through this year - a recent meeting of the IDM Data Council discussed what had topped each member's agenda during 2012 and whether that was likely to change in 2013.

Like a game of buzzword bingo, some of the themes were easy to predict, such as 'big data' and the proposed Data Protection Regulation. Others were more nuanced and reflected the fact that, while data may now have greater visibility than ever before, not everybody in the organization is entirely in love with what they see. 


\section{Cookies Law - Distraction or practice run?}

\section{Leading data trends in $\mathbf{2 0 1 2}$}

Cookies: It is hard to remember now quite how much uproar was being caused by the 'Cookies Law' during the first half of last year. Given a year to fall into compliance with the revised Directive, many digital marketers were still arguing about how justified the legal change was in the face of apparent consumer indifference.

As Robbie Burgess, Database Marketing Director, Reed Business Information, said: 'The Cookies Law really distracted us last year'. After a lot of fruitless protests, most website publishers have now complied and consumers have become used to seeing privacy notices and consent requests. Even the protesters appear to have fallen into line.

Mark Chipperfield, Head of Data Management, BBC TV Licensing, believes that the requirement may have actually put the data industry onto a better footing. 'The cookies moment has arguably achieved an acceleration of the relationship between consumers and their data, and that relationship becoming more equitable and transparent with the organisations that hold it. That's a good thing that should be embraced, a further move toward the democratisation of data, and organisations should take the opportunity to encourage and enable customers to update information, amend, add to their records and so on, as a way of building relationships. Such an approach should also serve to lessen the impact of new legislation'.

One benefit of this was to push permissions higher up the agenda. Adrian Gregory, Chief Executive, DQM Group, said: 'We've found a huge interest in data, not just from data professionals. Across the 1,000-plus people who attended our events last year, we have hundreds of different job titles. They are not just IT or data people, but right across the board. We have found there is as much interest in the data governance and compliance side as the insight piece'.

Data integration: Is there ever a year when integrating multiple data sources into a single view of the customer is not on the agenda? If 2012 proved anything, it is that this challenge has become harder as data sources continue to multiply, rather than easier as technology gets quicker and cheaper.

Matt Jarman, Associate Partner, Head of Data Insight, CACI, said: 'Linking web analytics and social media to known consumers was and continues to be a big thing for CACI and our clients. Trying to map all of that complex data together is something they are struggling with as often digital data is held in many different silos and at many different levels - both within an organisation and outside of it (eg, social). Over the past few years, brands have worked hard to integrate "known" or "identifiable" consumer data - now it is also about bringing in the more complex and disparate social and web behavioral data to provide a richer picture of consumers in order to drive more relevant comms'.

David Lloyd, Data Planning Director, TMW, noted that other trends have been forcing the pace: 'There is a lot of pressure from terms like 


\section{Building customer single view remains a challenge}

\section{Data has to make the business case}

"big data" - they go around the business and then the functions I work with get that pressure without the understanding of how to join those dots together, whatever the scale'.

Projects that were oriented around integration of conventional structured data still presented a challenge, even without these new digital streams. BBC TV Licensing was rebuilding an operational system with 50 separate touchpoints that had never been intended for use in the way that was now needed.

Ross Simson, BBC TV Licensing Insight, Analytics and Service Development Director, Capita, said that building a pilot to provide usable insights was vital to winning support for a full integration programme. 'We had to build an analytical data cube that the board could understand. They got that as a concept and funded it', he said. 'Where we have been struggling is with data building for that cube. Originally we called that team "master builders" - they now call themselves "master cobblers". Creating that view in six months was a big challenge'.

Tim Drye, Managing Director, DataTalk, argued that the emphasis on new data sets and big data risked creating a false impression of the potential for data integration. 'There is never going to be any database that tells you everything about a customer. One concept that has been getting traction is the notion that nobody is a single customer, they have multiple relationships. The biggest influence never gets tracked talking to your mates — and that always disrupts your analysis', he said. 'Social gives you an approximation of that, rather than an exact indicator'.

Return on investment: As data's role spread beyond its historical base in marketing and customer management out into the broader business, it came under new pressure to prove the value it was delivering. Morgan noted: 'It is about the line of sight through to value and benefit that can be created. It is about what needs to be changed in the business as a result of what you know and then showing the value to the business'.

Keith Jones, Head of Data Development, Royal Mail Data Services, noted the way investment decisions were changing. 'Business casing around data is difficult - getting non-data people at C-level to appreciate its value and to make a risk-based, not evidence-based decision. Evidence-based business cases for data integration will never succeed'.

One of the other big themes for 2013 - regulations and privacy will only serve to make that harder. Said Jones: 'C-level people are scared about privacy and permissions and less likely to take a riskbased decision as a result'.

Skills and training: With nearly 1,000 practitioners now having taken the IDM Award in Data Management since the IDM Data Council drove its development 2 years ago, it is evident that a skill gap exists in this space among marketers and managers with a broad-based 


\section{Analysts need to sell in their insights}

\section{New regulation dominates the agenda}

knowledge. Catching up with current practice is important to maintaining data's momentum, but deep problems exist.

As Morgan reported: 'It has been interesting to look at the skills we've got and those available in the market. Certain skills sets are really difficult to find - in some cases, it has taken us over a year to recruit. There is a great dearth of specialist skills'.

Jarman agreed, not least because the nature of the skills required has become more complex: 'The changing face of data employees is changing - they need to be a data planner, visualiser and data scientist. Increasingly analysts are client-facing, so we are hiring a different type of person now'.

Michael Green, Director of Insight, Transactis, faced the same problem: 'We also need to find people who are data literate and have a broad set of knowledge - that is extremely difficult. It is about identifying people who understand the value of data from a broad business perspective, over and above marketing, who can then go around the business and sell-in that opportunity'.

He added that the rise of data clashed with existing skills sets in some sectors - and that data tended to lose out. 'There is an education process people need to go through which can be a big cultural shift for many organisations. Retailers still work on the basis of a Monday morning trade meeting, whereas marketers are talking about optimisation. If the trading figures are down on a Monday, the board says get out there and shift more units, so the strategic marketing plan sometimes gets hijacked or, worse, ignored, leading to mixed messages to the consumer', said Green.

Nigel Grimes, Consultant, Teradata, believes that the current way marketing activity gets developed may need to change. 'The disconnect between data analysts, marketers, creative agencies and media agencies is still an issue. Creative briefs still want one message and proposition, but delivered in a segmented way. The whole point of a segmentation is different messages', he said. 'Agencies are still looking at cost per acquisition and cost per click - whether that person is a good customer six months down the line doesn't matter to them. That will change'.

\section{Predicted data trends for 2013}

Data Protection Regulation: No prizes for guessing the issue that hung over all discussion about data in the present year. The ongoing discussion of proposals for a new regulation informs so much about the thinking among members of the Council that it barely needed mentioning, except to reinforce how serious the threat to existing practices might be.

The industry is counting down to the expected first vote in late May on the proposals in the European Parliament. As Jones said: 'One of the challenges is that we can't just rely on DMA lobbying, we need to get more aggressive. The implications for business are dramatic and I don't think business has really understood what they mean'.

Gregory emphasized that the short timetable for such a major development could result in a worse-than-expected outcome. 
Finding the signal in the noise
Big data needs to be defined

\section{Rapid prototyping}

'The proposed Regulation will have a big impact and there won't be time to water them down. Although 900-plus amendments have been proposed, they won't be able to sort them out. So things will become much tougher for data. We'll need to ensure there is a proper trade-off with the consumer', he said.

Big data: The concept may already be subject to criticism, but there is no expectation of a decline in the interest being given to high volume, unstructured data sources from digital and social channels. With this focus has come confusion, said Lloyd: 'A lot of this year is about screening out the noise which is having a lot of impact on the business because people are now taking notice, but the way they perceive data is not necessarily correct. There is a lot of work to refocus them on what is important'.

Green said that there is a risk of history repeating itself. 'If Big Data shows commercial value, it will sustain its interest levels. But it could go the same way as CRM - companies will invest millions into systems but won't be able to show what that money delivered unless they capitalise on the Insight generated across the entire business. It's the same thing', he said.

While arguing about the description, other members of the Council were in little doubt about the continued focus on big data. 'It's new analytics, not big data - new ways of looking at large volumes of data', said Grimes.

'We have some clients in the US who are starting to use this stuff in new ways, such as fraud analytics. We have a poker client analysing in real time people who are trying to beat the banker and looking for fraud rings, or insurance companies recognising the same IP address among people setting up crashes to make a claim, or credit card companies recognising where a card is being used fraudulently. Marketers being able to analyse where a customer has really come from and putting a value across each part of that journey is really important, rather than just assigning to the last click', he said.

Simson argued that these types of activities will only serve to continue the rising importance of the data function. 'Big data is about new understanding - why customers do things in their journey and ensuring we change our systems in anticipation. I look after data, service, analytics and revenue-up - that is the part that allows you to make those changes and get a big difference in the revenue. The MD is calling us the brains of the organisation that needs to drive the business', he said.

Morgan agreed and foresees a refinement of the definition of big data. 'There is a massive opportunity within data from its ubiquity - customer and data are so intertwined, you are really talking about the same thing. You see that in the trust agenda and the need to be open about what you are doing. That is going to be a big thing in the coming years', he says.

Test and learn: A core discipline of direct marketing is re-emerging at the heart of digital marketing, although a skill gap in that sector is 


\section{Data becoming end-to- end}

making it harder to realize. Morgan added that the same technique has a much bigger business application in terms of prototypes and innovation. 'Can you create a prototype quickly to show the value and then get the investment, rather than the waterfall approach where you build it first and then show the value? Can you show the benefits early in order to de-risk a project?' he asked.

Changing the business culture: Marketers and data practitioners may not see themselves as being in the business of change management. Yet that is exactly what is resulting from the move to centre stage of data and the insights it yields.

Burgess noted that RBI has five major themes for the year that add up to a real change. 'We are revisiting the data assets within the business and integrating all those resources across the organisation. We are making sure we have the right resources and suppliers in place to deal with data tasks, making sure we have the right skills - we were very focused on functions, now we need people with end-to-end skills, so we are upskilling teams, which is a big learning curve for many of them', she said.

Burgess added: 'Embedding the data strategy into people's minds and trying to get data into the boardroom is a challenge - they are kind of interested and hear the buzzwords, like big data. We want them to understand the real challenges'.

External factors will further embed these kinds of changes, such as new accounting rules will mean that a company will have to analyse where profit and value sits in the business. Said Grimes: 'If you are doing bundled offers, you will have to account for where you are cross-subsidising to make sure you are not being anti-competitive'.

Data quality: An evergreen element of data management, data quality, has become even more complicated as new data sources come online. Social data is not validated at source and is highly dynamic, presenting a real challenge to maintaining its integrity on databases.

Burgess pointed out: 'One big thing I'm trying to get around is the amount of money we waste from poor data integrity and trying to put that right. We're trying to put a value on that and then flip it to how much we can make instead - that will then get the board's attention'.

Census data: It was pointed out that the release of Census 2011 may be the last occasion on which this information is made available for analysis, since the future of the once-a-decade poll is under discussion. The value of this data source was emphasized, not least because it sits outside of the controls of the proposed Data Protection Regulation.

Said Drye: 'The Census gives you a stable view of everybody. It is summarised at a high level of accuracy that gives you a lot of context in contrast to live data sets. It is a brilliant bit of data we are probably going to lose, so this may be the last time we get to do this'. 